\title{
Hepatitis B and C in Taiwanese patients with Schizophrenia: A Nationwide, Population-based study on prevalence, and healthcare utilization
}

\author{
Michael Yao-Hsien Wang ${ }^{1}$, Chao-Hsiun Tang ${ }^{2 *}$, Shih-Jen Tsai ${ }^{3}$, Chun-Jen Liu ${ }^{4}$ and Chi-Shin $\mathrm{Wu}^{5}$ \\ ${ }^{1}$ Medical Affairs, Janssen Pharmaceutical Taiwan, Taipei, Taiwan \\ ${ }^{2}$ School of Health Care Administration, Taipei Medical University, Taipei, Taiwan \\ ${ }^{3}$ Department of Psychiatry, Taipei Veteran General Hospital, Taipei, Taiwan \\ ${ }^{4}$ Department of Internal Medicine, National Taiwan University Hospital, Taipei, Taiwan \\ ${ }^{5}$ Department of Psychiatry, National Taiwan University Hospital and College of Medicine, National Taiwan University, Taipei, Taiwan
}

\begin{abstract}
Introduction: Hepatic viral infections (hepatitis B virus (HBV) and hepatitis $\mathrm{C}$ virus (HCV)) are endemic in Taiwan, and can progress to liver cirrhosis and hepatocellular carcinoma. Schizophrenia patients present substantial undiagnosed and untreated comorbidities compared with the general population. Hence, the prevalence of comorbid HBV/HCV infections in, and healthcare utilization by patients with schizophrenia should be determined.

Methods: This cross-sectional analysis of 5-year data from the Taiwan National Health Insurance administrative health insurance database evaluated the prevalence and relative risk (RR) of comorbid $\mathrm{HBV} / \mathrm{HCV}$ infections in schizophrenia patients $(\mathrm{n}=155,783$ ) versus non-schizophrenia controls ( $=467,349)$. Healthcare utilization was assessed using a two-part logistic regression and linear regression model.

Results: Schizophrenia patients had a greater prevalence of comorbid HBV/HCV infections than non-schizophrenia controls (HBV: $3.5 \%$ vs. $2.5 \%$, RR=1.51, 95\% confidence interval [CI]: 1.43-1.60, $p<0.0001 ; \mathrm{HCV}: 1.9 \%$ vs. $0.9 \%, \mathrm{RR}=2.1,95 \% \mathrm{CI}: 1.86-2.38, p<0.0001)$. Subgroup analysis showed a decreased risk of comorbid $\mathrm{HBV}$ or HCV infections in schizophrenia patients with increasing age. Significantly fewer schizophrenia patients underwent antiviral monitoring (alpha-fetoprotein checkup: $78.8 \%$ vs. $86.9 \%$ for HBV; $80.2 \%$ vs. $88.2 \%$ for $\mathrm{HCV}$; $p<0.0001$ ), and received fewer antiviral medications (oral antiviral therapy for HBV: $6.9 \%$ vs. $10.3 \%$; interferon-alpha therapy for HCV: $7.2 \%$ vs. $16.6 \%, p<0.0001)$ than non-schizophrenia controls. Discussion: In Taiwan, schizophrenia patients are significantly more susceptible to comorbid viral infections versus the general population. This study reinforces the urgency of timely diagnosis and interventional treatment in this underserved population.
\end{abstract}

\section{Introduction}

Taiwan is a hyper-endemic region for liver diseases such as cirrhosis and hepatocellular carcinoma (HCC), and infection with hepatitis B virus (HBV) and hepatitis $\mathrm{C}$ virus (HCV) are primary etiologic factors $[1,2]$. Before the launch of the universal childhood $\mathrm{HBV}$ vaccination policy in 1984, the prevalence rate of HBV infection in Taiwan was $15 \%$ to $20 \%$ [3]. Studies spanning a 23 -year post-vaccination period showed a significant decrease in chronic hepatitis $\mathrm{B}(\mathrm{CHB})$ infections (hepatitis B surface antigen [HbsAg] seropositive for $\geq 6$ months) with HBsAg seropositivity reducing from $\sim 14.3 \%$ up to $\sim 0.9 \%$ [4-6]. Further, mortality due to fulminant hepatic failure and HCC also dramatically decreased following implementation of the vaccination program [7]. In a large-scale Taiwanese survey undertaken for evaluating HBV and HCV seroprevalence, increased HBsAg and anti-HCV seroprevalence rates ( $17.3 \%$ and $4.4 \%$, respectively) were observed due to the inclusion of subjects born prior to the vaccination era [2]. Recent results from a literature review evaluating the burden of $\mathrm{HCV}$ in Asia confirmed HCV infection rates of $1.8 \%$ to $5.5 \%$ in Taiwan [8].

Though HBV infection rates in Taiwan have declined over the last 20 years, $\mathrm{CHB}$ and chronic hepatitis $\mathrm{C}$ ( $\mathrm{CHC}$; positive for antibodies to $\mathrm{HCV}$ [anti-HCV] and HCV RNA) remain endemic. HBV and
HCV are transmitted through percutaneous or mucosal exposure to infected blood or other body fluids [9] and from mother to child [10]. Continued transmission occurs in low- and middle-income countries such as Taiwan, where unsafe medical practices (e.g., use of unsterilized syringes or needles during renal dialysis, blood transfusions, and surgeries) and unprotected sex are, unfortunately, common. Further, vaccine failure because of non-compliance and breakthrough infection also contribute to residually high CHB rates [11].

Currently, treatment is initiated primarily in those with chronic viral hepatitis $\mathrm{B}$ or $\mathrm{C}[38,39]$. Immunomodulators (standard and pegylated interferon [PEG-IFN]) and nucleos(t)ide analogs (lamivudine, adefovir, entecavir, telbivudine, and tenofovir) [39] are treatment options for $\mathrm{CHB}$, while PEG-IFN, ribavirin, protease inhibitors (boceprevir, simeprevir, and telaprevir), NS5A inhibitors,

Correspondence to: Chao-Hsiun Tang, School of Health Care Administration, Taipei Medical University, Taipei, 110-Taiwan, Tel: +886-988573529; Fax: +88623789788; Email: chtang@tmu.edu.tw

Key words: comorbidity, healthcare utilization, hepatitis, prevalence, schizophrenia Received: April 16, 2017; Accepted: May 23, 2017; Published: May 26, 2017 
and nucleotide analog polymerase inhibitors (sofosbuvir) [12] are used to treat CHC. However, prohibitively high costs prevent easy access to antiviral therapy in developing countries such as Taiwan, and precludes treatment in many patients [13]. In addition to at-risk groups (e.g., parental drug users; immunosuppressed, hemophilia, and dialysis patients; and healthcare workers), HBV and HCV infection rates are high among those with serious mental illnesses [14-17] such as schizophrenia. According to data from the National Health Insurance Research Database (NHIRD), the 1-year prevalence rate of schizophrenia in Taiwan was 3.34 per 1000 , with a 6-year (cumulative, 1996-2001) prevalence rate of 6.42 per 1000 [18]. Patients with schizophrenia are significantly more likely to have increased and more severe comorbidities than the general population or those without schizophrenia with up to one-third having $\geq 3$ chronic medical comorbidities, including hypothyroidism, diabetes, hypertension, and hepatitis [19-21]. However, many of these patients do not receive treatment for their comorbidities, potentially because of a general lack of or suboptimal medical treatment, inadequate patient awareness, and/or inability of the patient to effectively communicate symptoms with a healthcare provider [19-25]. Hence, diagnosis of comorbid medical conditions is often delayed or missed altogether [21].

Guidelines recommend that patients with $\mathrm{CHB}$ or $\mathrm{CHC}$ be evaluated to determine whether treatment should be initiated [26]; however, the rate of comorbid HBV or HCV infection among patients with schizophrenia in Taiwan is ill-defined, as is the degree of appropriate diagnostic testing and treatment. The aims of this study, therefore, were to determine the prevalence of HBV and HCV infection among Taiwanese people with and without schizophrenia, and the level of healthcare utilization in patients with schizophrenia and comorbid HBV or HCV infection compared with a non-schizophrenia control population.

\section{Methods}

\section{Study design}

In this cross-sectional study, data for patients with and without schizophrenia (non-schizophrenia controls) were extracted from a nationwide, population-based, health insurance claims dataset in Taiwan. Prevalence of comorbid HBV or HCV infection, as well as consequent healthcare utilization were determined. The study was approved by the respective Institutional Review Boards.

\section{Data source}

Patient-level data were obtained for a 5-year period (20072011) from the Taiwan National Health Research Institute Database (NHIRD), which contains National Health Insurance (NHI) claim files and the data files of all treated individuals and NHI-contracted healthcare providers. The NHI is a mandatory, social health insurance program with extensive healthcare benefits, and covers nearly $99 \%$ of the Taiwanese population [36]. The NHIRD is a nationwide population-based database established by the Taiwan National Health Research Institute (NHRI) and the Bureau of the NHI. This database includes annually updated healthcare data and medical utilization information from all contracted hospitals and providers. Each patient is assigned a unique identification number, which allows the associated computerized patient information to be accessed over time. Patient demographics; medical diagnoses; prescribed medications; healthcare utilization; and medical services availed, including specialist referrals and hospital admissions, were determined from this database.

\section{Study and control cohorts}

Patients with schizophrenia were identified based on having $\geq 2$ outpatient visits or 1 inpatient visit with a primary or secondary diagnosis (International Classification of Diseases Ninth RevisionClinical Modification [ICD-9-CM] code of 295 or catastrophic certificate of 295 within 1 year during 2007 to 2011. After excluding patients with schizophrenia, the 1:3 matched-pair control population (non-schizophrenia controls) was identified from the 2005 sample cohort files and matched to the study cohort by age and gender.

Patients with $\geq 2$ outpatient visits or 1 inpatient record and primary ICD-9-CM codes of 070.2, 070.3, and V026.1 were defined as HBVinfected patients. Patients with $\geq 2$ outpatient visits or 1 inpatient record and primary ICD-9-CM codes of 070.41, 070.44, 070.51, 070.54, and V026.2 were defined as HCV-infected patients [37].

\section{Assessments}

The prevalence of HBV or HCV infection among patients with schizophrenia and the non-schizophrenia controls was calculated. The frequency of routine antiviral monitoring (alpha-fetoprotein [AFP] detection and abdominal sonography) and antiviral treatment within a year of initial hepatitis diagnosis was recorded. In Taiwan, the mainstay of HBV and HCV treatment is oral antiviral medication and interferon (IFN)-alpha therapy, respectively; hence, these treatments were considered representative of antiviral treatment and were monitored.

\section{Statistical analyses}

The chi-squared test was used to compare the demographics of the schizophrenia patients and the non-schizophrenia controls. In addition, the prevalence of $\mathrm{HBV}$ or $\mathrm{HCV}$ infection stratified by sex and age were compared in the schizophrenia patients versus the non-schizophrenia controls. Sex- and age-adjusted logistic regression analyses were performed to evaluate the relative risk (RR) of having comorbid HBV or HCV infection in schizophrenia patients versus non-schizophrenia controls. Healthcare utilization was analysed by using logistic regression. Statistical significance was set at $p \leq 0.05$, and $95 \%$ confidence intervals (CI) were determined. All statistical analyses were performed using SAS statistical software, version 9.3.

\section{Results}

\section{Demographics}

The demographics of the study (schizophrenia: $n=155,783$ ) and control (no schizophrenia: $n=467,349$ ) cohorts were similar (Table 1). The proportion of males (52.7\%) and females (47.3\%) was roughly equivalent, and over two-thirds of the patients were aged between 30 and 59 years, with the highest concentration in the 40 to 49 years old age group.

\section{Prevalence of and risk for $\mathrm{HBV}$ and $\mathrm{HCV}$ infection}

A greater number of schizophrenia patients than non-schizophrenia controls had HBV (3.5\% vs. $2.5 \%)$ or $\mathrm{HCV}(1.9 \%$ vs. $0.9 \%)$ infection, regardless of age or sex (Table 2). Schizophrenia patients were also at a significantly higher RR of having HBV or HCV infection than nonschizophrenia controls (HBV: sex- and age-adjusted $\mathrm{RR}=1.51,95 \%$ CI: $1.43-1.60, p<0.0001$; HCV: sex- and age-adjusted RR=2.1; 95\% CI: $1.86-2.38 ; p<0.0001$ ) (Figure 1). 

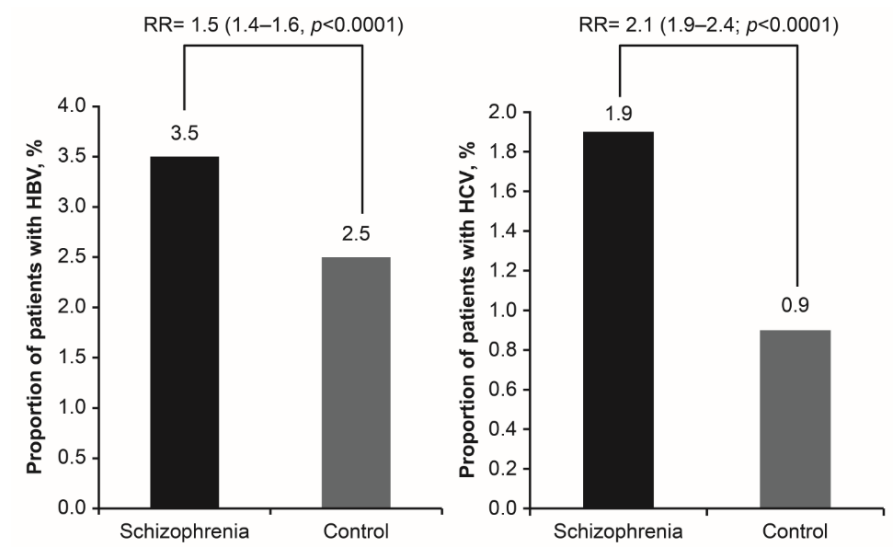

Figure 1. Relative risk of comorbid HBV or HCV in patients with schizophrenia versus non-schizophrenia controls

Table 1. Demographics of study and control cohorts

\begin{tabular}{|c|c|c|}
\hline & SCHIZOPHRENIA & $\begin{array}{c}\text { NON } \\
\text { SCHIZOPHRENIA }\end{array}$ \\
\hline & $\mathbf{n ~ ( \% )}$ & $\mathbf{n}(\mathbf{\%})$ \\
\hline Total & 155,783 & 467,349 \\
\hline Gender & & \\
\hline Male & $82,108(52.7)$ & $246,324(52.7)$ \\
\hline Female & $73,675(47.3)$ & $221,025(47.3)$ \\
\hline Age (years) & & \\
\hline$<\mathbf{2 0}$ & $2,481(1.6)$ & $47,858(1.9)$ \\
\hline $\mathbf{2 0 - 2 9}$ & $15,664(10.1)$ & $103,555(22.2)$ \\
\hline $\mathbf{3 0 - 3 9}$ & $34,053(21.9)$ & $121,464(26.0)$ \\
\hline $\mathbf{4 0 - 4 9}$ & $41,461(26.6)$ & $99,039(21.2)$ \\
\hline $\mathbf{5 0 - 5 9}$ & $33,133(21.3)$ & $47,546(10.2)$ \\
\hline $\mathbf{6 0 - 6 9}$ & $15,999(10.3)$ & $39,782(8.5)$ \\
\hline $\mathbf{2 7 0}$ & $12,992(8.3)$ & \\
\hline
\end{tabular}

Risk factors predicting for comorbid HBV and HCV infections

Multivariate regression analysis showed that after controlling for age and sex, schizophrenia patients were at a higher risk for having HBV or HCV infections. Subgroup analysis showed that the risk of schizophrenia patients having comorbid HBV or HCV infection decreased with increasing age (for age group $<30$ years: $\mathrm{RR}=15.12[95 \%$ CI: 7.26-31.50, $p<0.0001$ ] for HBV; $\mathrm{RR}=39.67$ [95\% CI: $10.24-153.70$, $p<0.0001]$ for $\mathrm{HCV}$, for age group 30-59 years: $\mathrm{RR}=1.52$ [95\% CI: 1.17-1.97, $p=0.0019$ ] for HBV; $\mathrm{RR}=2.79$ [95\% CI: $1.88-4.14, p<0.0001$ ] for $\mathrm{HCV}$, and for age group $>60$ years: $\mathrm{RR}=1.13$ [95\% CI: $1.03-1.25$, $p=0.0110$ ] for HBV; RR $=1.33$ [95\% CI: $1.04-1.69, p=0.0206$ for HCV] (Figure 2).

\section{Healthcare utilization}

The proportion of patients undergoing routine antiviral monitoring or antiviral treatment was lower among schizophrenia patients with comorbid hepatitis B or C than non-schizophrenia controls (Table 3, Figure S1). Significantly fewer schizophrenia patients with comorbid HBV infection underwent AFP check-ups $(78.8 \%$ vs. $86.9 \%, p<0.0001)$ and abdominal sonography (86. $8 \%$ vs. $90 \%, p=0.0006)$ than nonschizophrenia controls. Similarly, significantly fewer schizophrenia patients with comorbid $\mathrm{HCV}$ infection underwent AFP check-ups ( $80.2 \%$ vs. $88.2 \%, p<0.0001)$. Adjusted RRs indicated that these patients were also significantly less likely than non-schizophrenia controls to undergo routine monitoring and follow-up. Likewise, the proportion of schizophrenia patients with comorbid HBV or HCV receiving oral antiviral medication $(6.9 \%$ vs. $10.3 \%, p<0.0001)$ or IFN therapy (7.2\% vs. $16.6 \%, p<0.0001)$ was significantly lower compared with non-schizophrenia controls. Adjusted RRs (0.64 [95\% CI: 0.57-0.73], $p<0.0001$, and 0.35 [95\% CI: $0.29-0.43] p<0.0001$ ), for comorbid $\mathrm{HBV}$ and $\mathrm{HCV}$ infections, respectively, indicated a significantly lower likelihood of these patients receiving medical treatment (Supplementary Figure 1).

Table 2. Prevalence of HBV and HCV infections among patients with schizophrenia and non-schizophrenia controls

\begin{tabular}{|c|c|c|c|c|}
\hline \multicolumn{4}{|c|}{$\mathrm{HBV}$} & \multirow{2}{*}{$\begin{array}{c}\text { HCV } \\
\text { Control }\end{array}$} \\
\hline & Schizophrenia & Control & Schizophrenia & \\
\hline & n (\%) & n (\%) & n (\%) & $\mathrm{n}(\%)$ \\
\hline Total & $5,520(3.5)$ & $11,475(2.5)$ & $2,924(1.9)$ & $4,198(0.9)$ \\
\hline \multicolumn{5}{|l|}{ Gender } \\
\hline Male & $3,705(4.5)$ & $7,631(3.1)$ & $1,836(2.2)$ & $2,304(0.9)$ \\
\hline Female & $1,815(2.5)$ & $3,844(1.7)$ & $1,088(1.5)$ & $1,894(0.9)$ \\
\hline \multicolumn{5}{|l|}{ Age } \\
\hline$<30$ & $212(1.2)$ & $70(0.1)$ & $78(0.4)$ & $11(0.0)$ \\
\hline $30-59$ & $4,525(4.2)$ & $9,323(2.9)$ & $2,057(1.9)$ & $2,384(0.7)$ \\
\hline$\geq 60$ & $783(2.7)$ & $2,082(2.4)$ & $789(2.7)$ & $1,803(2.1)$ \\
\hline \multicolumn{5}{|l|}{ Male } \\
\hline \multicolumn{5}{|l|}{ Age } \\
\hline$<30$ & $140(1.4)$ & $46(0.1)$ & $52(0.5)$ & $10(0.0)$ \\
\hline $30-59$ & $3,129(5.3)$ & $6,401(3.6)$ & $1,373(2.3)$ & $1,485(0.8)$ \\
\hline$\geq 60$ & $436(3.4)$ & $1,184(3.0)$ & $411(3.2)$ & $809(2.1)$ \\
\hline \multicolumn{5}{|l|}{ Female } \\
\hline \multicolumn{5}{|l|}{ Age } \\
\hline$<30$ & $72(0.9)$ & $24(0.1)$ & $26(0.3)$ & $1(0.0)$ \\
\hline $30-59$ & $1,396(2.8)$ & $2,922(2.0)$ & $684(1.4)$ & $899(0.6)$ \\
\hline$\geq 60$ & $347(2.2)$ & 898 (1.9) & $378(2.4)$ & $994(2.1)$ \\
\hline
\end{tabular}

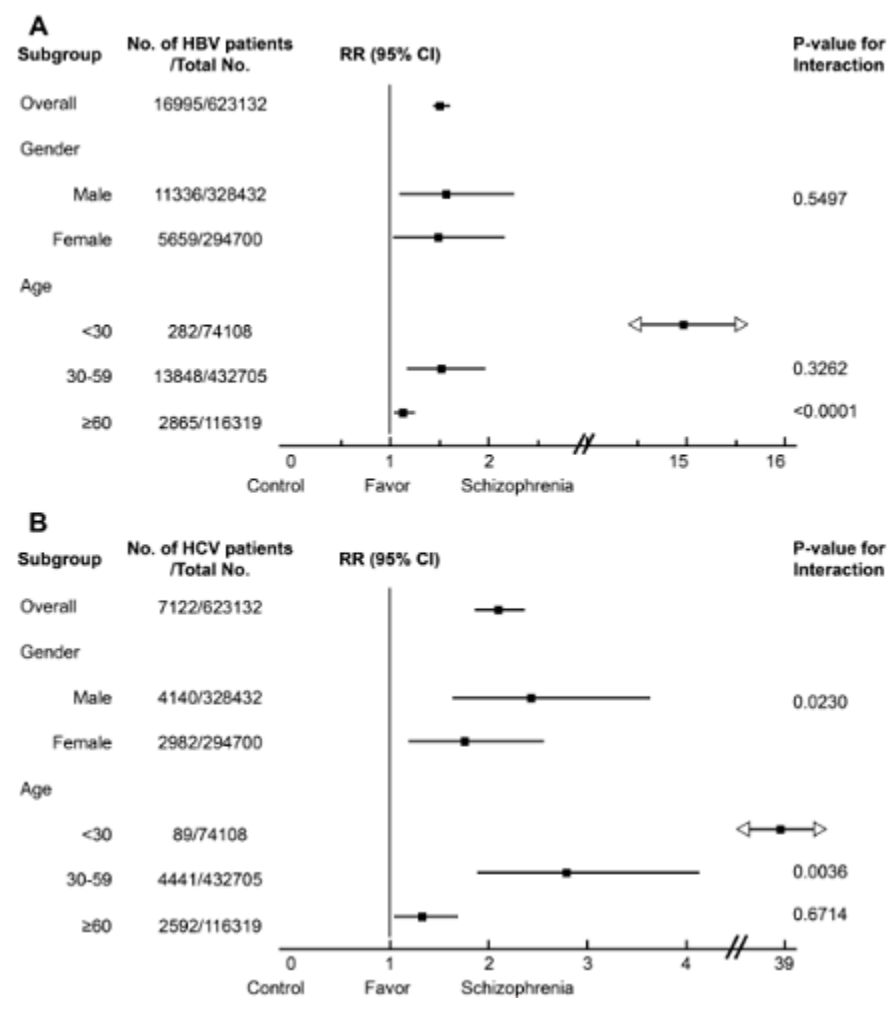

Figure 2. Relative risk of (a) HBV infection or (b) HCV infection, in age and sex subgroups among patients with or without schizophrenia 
Table 3. Medical utilization with comorbid HBV/HCV infections among patients with schizophrenia versus non-schizophrenia controls

\begin{tabular}{|c|c|c|c|c|c|c|c|c|c|c|}
\hline & \multicolumn{5}{|c|}{ HBV } & \multicolumn{5}{|c|}{ HCV } \\
\hline & SCH & Control & aRR & $95 \% \mathrm{CI}$ & $p$ & SCH & Control & aRR & $95 \% \mathrm{CI}$ & $p$ \\
\hline & $\mathrm{n}(\%)$ & $\mathrm{n}(\%)$ & & & & $\mathrm{n}(\%)$ & $\mathrm{n}(\%)$ & & & \\
\hline Oral antiviral therapy & $379(6.87)$ & $1,187(10.34)$ & 0.64 & $0.57-0.73$ & $<0.0001$ & & & & & \\
\hline Interferon therapy & $44(0.80)$ & $139(1.21)$ & 0.66 & $0.47-0.93$ & 0.0179 & $211(7.22)$ & $697(16.60)$ & 0.35 & $0.29-0.43$ & $<.0001$ \\
\hline Alpha-fetoprotein checkup & $4,350(78.80)$ & $9,975(86.93)$ & 0.57 & $0.50-0.66$ & $<0.0001$ & $2,345(80.20)$ & $3,704(88.23)$ & 0.62 & $0.55-0.71$ & $<.0001$ \\
\hline Abdominal sonography & $4,790(86.78)$ & $10,331(90.03)$ & 0.76 & $0.64-0.89$ & 0.0006 & $2,664(91.11)$ & $3,904(93.00)$ & 0.92 & 0.78-1.09 & 0.3495 \\
\hline
\end{tabular}

For $\mathrm{HBV}$ and $\mathrm{HCV}$, the mainstay of treatment is oral antiviral medication and interferon alpha therapy (frequently with ribavirin), respectively, which have been monitored in this study.

$R R=0.64(0.57-0.73 ; p<0.0001)$

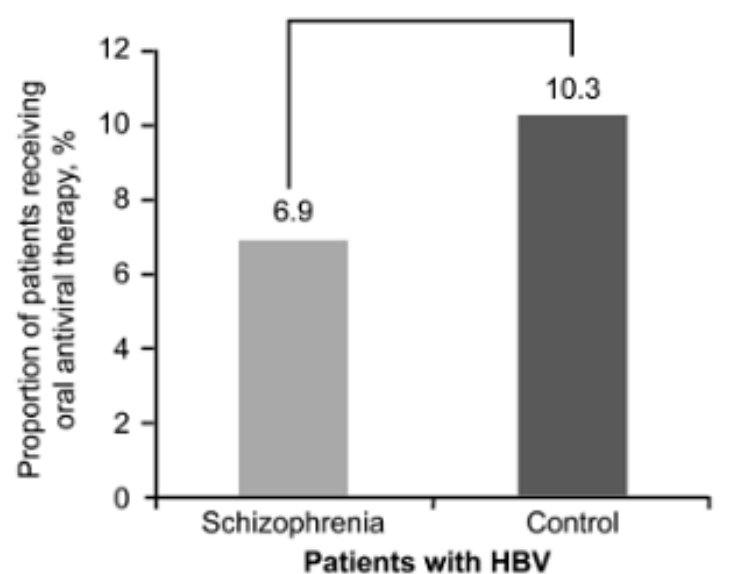

$\operatorname{RR}=0.35(0.29-0.43 ; p<0.0001)$

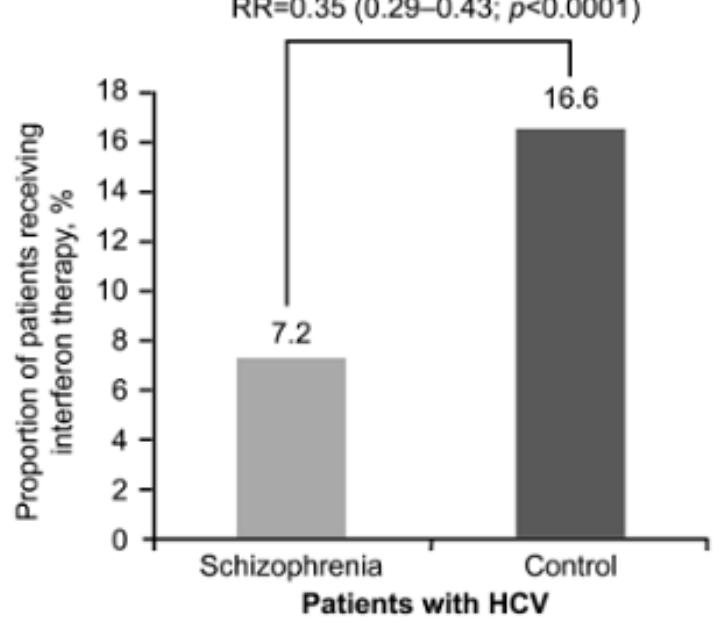

Figure S1. Differences in medical utilization between patients with schizophrenia and comorbid HBV/HCV infection versus non-schizophrenia controls

\section{Discussion}

The results of this study indicate that, in Taiwan, the prevalence of $\mathrm{HBV}(3.5 \%$ vs. $2.5 \%)$ and $\mathrm{HCV}(1.9 \%$ versus $0.9 \%)$ infection is significantly higher among patients with schizophrenia versus those without schizophrenia. The low prevalence rates of HBV infection observed in the general population (2.5\%) may be attributed to the inclusion of the post-vaccination age group of $<30$ years in our dataset. Due to the universal HBV vaccination policy, this age group has a greater probability of being vaccinated as compared to the other age groups. The results also show that patients with schizophrenia have a significantly higher risk for having HBV and HCV infections than the general population. The subgroup analysis shows a reduced risk of comorbid HBV or HCV infections in schizophrenia patients with increasing age. The higher prevalence of hepatitis infections with age reiterates the effectiveness of the vaccination program; however, the high RRs in the younger age group emphasize the need for ensuring successful implementation of vaccination through the entire population. Further, healthcare utilization (routine antiviral monitoring and antiviral treatment) was lower among schizophrenia patients with comorbid HBV or HCV infections versus the nonschizophrenia controls.

These results, in general, are consistent with those from studies conducted in other countries [19,20,27]. An analysis of data from the US National Hospital Discharge Survey showed that hospitalized patients with schizophrenia had more comorbidities, including viral hepatitis, than those with other primary diagnoses [20]. Furthermore, according to a retrospective longitudinal claims dataset analysis, schizophrenia patients were significantly more likely than patients without schizophrenia of having hepatitis C (odds ratio [95\% CI]: 7.54 [3.55 to 15.99]) [19]. Finally, 7.1\% of veterans with schizophrenia versus $2.5 \%$ of veterans without any severe mental illness had HCV infection in a cross-sectional data analysis of the Veteran's Affairs National Psychosis Registry [27]. In contrast to our results and the studies mentioned above, two studies showed that the prevalence of HBV or HCV infection was not significantly different between patients with schizophrenia and the general population $[15,28]$. A study conducted in Jordan indicated a higher but not significantly different rate of HBV infection among patients with chronic schizophrenia versus the general population, suggesting an increased risk in this population [15]. In the second study, which was also conducted with the Taiwanese population, HBV and HCV seroprevalence rates in institutionalized schizophrenia patients were similar to those in the general population. However, the authors acknowledged that the carefully controlled environment of the institutionalized setting of these chronic schizophrenia patients might have prevented at-risk behavior [28]. Further, the results were based on schizophrenia patients from a single institute and could not be extrapolated to the general population. In contrast, our study was based on a national insurance claims database, which encompassed a heterogeneous healthcare-seeking population, including hospitalized patients, which makes the results more representative of the Taiwanese population.

This study used data from a large, nationwide, population-based health insurance claims database from the NHI, which insures almost 99\% of the Taiwanese population. In addition, the database includes physicians from disparate clinical settings. Hence, the results effectively capture a diverse yet representative patient population subjected to different treatment approaches and, ultimately, reflect real-world clinical practice in Taiwan. In contrast, some of the aforementioned studies $[27,28]$ used convenience sampling such as institutionalized patients or patients in the US Veteran Affairs system; therefore, the results are not representative or generalizable. A limitation of employing a health insurance claims database, however, is the restricted data availability, which is limited to patients seeking treatment and 
receiving a diagnosis. Exclusion of patients not captured by this system will skew the reported prevalence, which may be lower than the actual numbers. Failure of the physician to provide medical assessment or an incorrect diagnosis can also contribute to a lower reported prevalence.

Multifactorial reasons contribute to the increased prevalence, higher risk, and lower healthcare utilization observed among Taiwanese patients with schizophrenia and comorbid viral hepatitis infections versus the general population. Patient-related reasons included high-risk behavior, lack of awareness [29] and inability to clearly communicate their medical condition [22], and low adherence to the evaluation [29] and treatment process. Physician-contributed reasons are incorrect diagnoses or hesitance in treatment by the primary care physician, and reluctance or lack of training of psychiatrists to perform a physical examination or administer appropriate check-ups [30]. Low socioeconomic conditions and the lack of an integrated medical and mental-healthcare facility contribute to the failure of this system to provide optimal quality healthcare to this population [31].

Antiviral therapies such as IFN and ribavirin were the reimbursed treatments for HCV in Taiwan during the analyzed period (20072011), and oral antiviral medications or IFN were the standard-of-care medications for HBV; however, therapies such as IFN are typically contraindicated in mental illness patients with mood instabilities because of psychiatric side effects [14]. However, in several studies, the psychiatric side effects (mania and depression) with antiviral/IFN-alpha therapy for $\mathrm{CHC}$ in patients with schizophrenia were not exacerbated and were comparable to those in patients without schizophrenia $[32,33]$. Thus, antiviral therapy may be considered in this population, especially with close monitoring of psychiatric symptoms.

Collectively, the results from this study emphasize the need for better viral hepatitis surveillance among patients with schizophrenia, and increased interventional treatment when appropriate, especially in a country like Taiwan that is hyperendemic for viral hepatitis and where access to antiviral medication is limited. A proposed solution is an integrated healthcare model for comorbid disease management in patients with severe mental illness [34]. The model should be costeffective [35] and integrate psychiatric and somatic healthcare facilities (e.g., a single location for providing mental and medical healthcare) as separate geographical locations for various facilities deter patients from seeking medical attention [35]. An appropriately trained psychiatrist [34] should also be involved. In conjunction, coordination, and communication across different healthcare providers/specialties [35] are needed to successfully engage with patients to ensure adherence [29].

\section{Conclusion}

In Taiwan, the prevalence of and risk for viral hepatitis (HBV and $\mathrm{HCV}$ ) infections is higher among patients with schizophrenia than the general population. Healthcare resources are also under-utilized in this population. Findings from this study underscore the need for appropriate healthcare models to increase viral hepatitis surveillance, ensure timely diagnosis, and promote delivery of optimal medication in this underserved population.

\section{Author contributions}

CHT contributed to conception, design, planning of the study, acquisition of data, analysis and interpretation of data; MYHW, SJT, CJL, and CSW contributed to analysis and interpretation of data; MYHW contributed to drafting of the manuscript; CHT, SJT, CJL, and CSW critically revised the manuscript for important intellectual content. All authors had full access to the manuscript and take responsibility for the integrity of the data and the accuracy of the data analysis. All authors have approved the manuscript and agree with submission to your esteemed journal.

\section{Acknowledgments}

Editorial support, in the form of medical writing, assembling tables and creating high-resolution images based on author's detailed directions, collating author comments, copyediting, fact checking, and referencing, was provided by Aparna Nori, $\mathrm{PhD}$ of Cactus Communications and funded by Janssen Pharmaceutical, Taiwan.

This study was funded by Janssen Pharmaceutical, Taiwan. The funding source had no involvement in the study design, collection, analysis and interpretation of data, or in the writing and decision to submit the article for publication.

\section{References}

1. Chen CJ, Yu MW, and Liaw YF (1997) Epidemiological characteristics and risk factors of hepatocellular carcinoma. J Gastroenterol Hepatol 12: S294-S308. [Crossref]

2. Chen CH, Yang PM, Huang GT, Lee HS, Sung JL, et al. (2007) Estimation of seroprevalence of hepatitis B virus and hepatitis $\mathrm{C}$ virus in Taiwan from a large-scale survey of free hepatitis screening participants. J Formos Med Assoc 106: 148-155. [Crossref]

3. Chen DS (1987) Hepatitis B virus infection, its sequelae, and prevention in Taiwan Neoplasms of the Liver (pp. 71-80). Tokyo: Springer-Verlag.

4. Lu JJ, Cheng CC, Chou SM, Hor CB, Yang YC, et al. (2009) Hepatitis B immunity in adolescents and necessity for boost vaccination: 23 years after nationwide hepatitis $\mathrm{B}$ virus vaccination program in Taiwan. Vaccine 27: 6613-6618. [Crossref]

5. Chen SM, Kung CM, Yang WJ, and Wang HL (2011) Efficacy of the nationwide hepatitis B infant vaccination program in Taiwan. J Clin Virol 52: 11-16. [Crossref]

6. Ni YH, Chang MH, Wu JF, Hsu HY, Chen HL, et al. (2012) Minimization of hepatitis $\mathrm{B}$ infection by a 25-year universal vaccination program. $J$ Hepatol 57: 730-735. [Crossref]

7. Shepard CW, Simard EP, Finelli L, Fiore AE, and Bell BP (2006) Hepatitis B virus infection: Epidemiology and vaccination. Epidemiol Rev 28: 112-125. [Crossref]

8. Bennett H, Waser N, Johnston K, Kao JH, Lim YS, et al. (2015) A review of the burden of hepatitis C virus infection in China, Japan, South Korea and Taiwan. Hepatol Int 9 : 378-390. [Crossref]

9. Lee MH, Yang HI, Yuan Y, L'Italien G, \& Chen CJ (2014) Epidemiology and natural history of hepatitis C virus infection. World J Gastroenterol 20: 9270-9280. [Crossref]

10. Yeung CY, Lee HC, Chan WT, Jiang CB, Chang SW, et al. (2014) Vertical transmission of hepatitis C virus: Current knowledge and perspectives. World J Hepatol 6: 643-651. [Crossref]

11. Ni YH, Huang LM, Chang MH, Yen CJ, Lu CY, et al. (2007) Two decades of universal hepatitis B vaccination in Taiwan: Impact and implication for future strategies. Gastroenterology 132: 1287-1293. [Crossref]

12. Seifert LL, Perumpail RB, Ahmed A (2015) Update on hepatitis C: Direct-acting antivirals. World J Hepatol 7: 2829-2833. [Crossref]

13. Lemoine M, Nayagam S, Thursz M (2013) Viral hepatitis in resource-limited countries and access to antiviral therapies: current and future challenges. Future Virol 8: 371 380. [Crossref]

14. Rosenberg SD, Goodman LA, Osher FC, Swartz MS, Essock SM, et al. (2001) Prevalence of HIV, hepatitis B, and hepatitis C in people with severe mental illness. Am J Public Health 91: 31-37. [Crossref]

15. Said WM, Saleh R, and Jumaian N (2001) Prevalence of hepatitis B virus among chronic schizophrenia patients. Eastern Mediterranean Health Journal 7: 526-530.

16. Zhu H, Liu X, Xue Y, Shen C, Li Y, et al. (2015) Seroepidemiology of hepatitis B virus infection among Chinese schizophrenia patients. J Infect Dev Ctries 9: 512-518. [Crossref]

17. Goldberg RW (2004) Hepatitis and HIV screening, education, and treatment for adults with serious mental illness. General Hospital Psychiatry 26: 167-168.

18. Chien IC, Chou YJ, Lin CH, Bih SH, Chou P, et al. (2004) Prevalence and incidence of schizophrenia among national health insurance enrollees in Taiwan, 1996-2001. Psychiatry Clin Neurosci 58: 611-618. [Crossref] 
19. Carney CP, Jones L, and Woolson RF (2006) Medical Comorbidity in Women and Men with Schizophrenia: A Population-Based Controlled Study. J Gen Intern Med 21: 1133-1137. [Crossref]

20. Weber NS, Cowan DN, Millikan AM, and Niebuhr DW (2009) Psychiatric and general medical conditions comorbid with schizophrenia in the National Hospital Discharge Survey. Psychiatr Serv 60: 1059-1067. [Crossref]

21. Dixon L, Postrado L, Delahanty J, Fischer PJ, Lehman A (1999) The association of medical comorbidity in schizophrenia with poor physical and mental health. $J$ Nerv Ment Dis 187: 496-502. [Crossref]

22. Lawrie SM, Parsons C, Patrick J, Masson S, Sussmann J, et al. (1996) A controlled trial of general practitioners' attitudes to patients with schizophrenia. Health Bull (Edinb) 54: 201-203. [Crossref]

23. Newman SJ (1994) The housing and neighborhood conditions of persons with severe mental illness. Hosp Community Psychiatry 45: 338-343. [Crossref]

24. Folsom DP, McCahill M, Bartels SJ, Lindamer LA, Ganiats TG, et al. (2002) Medica comorbidity and receipt of medical care by older homeless people with schizophrenia or depression. Psychiatr Serv 53: 1456-1460. [Crossref]

25. Roberts L, Roalfe A, Wilson S, Lester H (2007) Physical health care of patients with schizophrenia in primary care: a comparative study. Fam Pract 24: 34-40. [Crossref]

26. Sherman M, Shafran S, Burak K, Doucette K, Wong W, et al. (2007) Management of chronic hepatitis C: Consensus guidelines. Canadian Journal of Gastroenterology and Hepatology 21(Suppl C), 25C-34C.

27. Himelhoch S, Mccarthy JF, Ganoczy D, Medoff D, Kilbourne A, et al. (2009) Understanding associations between serious mental illness and hepatitis $\mathrm{C}$ virus among veterans: A national multivariate analysis. Psychosomatics 50: 30-37. [Crossref]

28. Hung CC, Loh EW, Hu TM, Chiu HJ, Hsieh HC, et al. (2012) Prevalence of hepatitis B and hepatitis $\mathrm{C}$ in patients with chronic schizophrenia living in institutions. J Chin Med Assoc 75: 275-280. [Crossref]

29. Rifai MA, Moles JK, and Short DD (2006) Hepatitis C treatment eligibility and outcomes among patients with psychiatric illness. Psychiatric Services 57: 570-572.
30. Mitchell AJ, Lord O, and Malone D (2012) Differences in the prescribing of medication for physical disorders in individuals with v. without mental illness: Meta-analysis. $\mathrm{Br} \mathrm{J}$ Psychiatry 201: 435-443. [Crossref]

31. Levinson Miller C, Druss BG, Dombrowski EA, and Rosenheck RA (2003) Barriers to primary medical care among patients at a community mental health center. Psychiatr Serv 54: 1158-1160. [Crossref]

32. Schaefer M, Schmidt F, Folwaczny C, Lorenz R, Martin G, et al. (2003) Adherence and mental side effects during hepatitis $\mathrm{C}$ treatment with interferon alfa and ribavirin in psychiatric risk groups. Hepatology 37: 443-451. [Crossref]

33. Huckans M, Mitchell A, Pavawalla S, Morasco BJ, Ruimy S, et al. (2010) The influence of antiviral therapy on psychiatric symptoms among patients with hepatitis $\mathrm{C}$ and schizophrenia. Antivir Ther 15: 111-119. [Crossref]

34. Golomb BA, Pyne JM, Wright B, Jaworski B, Lohr JB, et al. (2000) The role of psychiatrists in primary care of patients with severe mental illness. Psychiatr Serv 51: 766-773. [Crossref]

35. Willenbring ML (2005) Integrating care for patients with infectious, psychiatric, and substance use disorders: concepts and approaches. AIDS 19 Suppl 3: S227-237. [Crossref]

36. National Health Insurance Research Database, Taiwan. URL: http://nhird.nhri.org.tw/en/

37. Liu CJ, Chu YT, Shau WY, Kuo RN, Chen PJ, et al. (2014) Treatment of patients with dual hepatitis $\mathrm{C}$ and $\mathrm{B}$ by peginterferon $\hat{\mathrm{I}} \pm$ and ribavirin reduced risk of hepatocellular carcinoma and mortality. Gut 63: 506-514. [Crossref]

38. World Health Organization (2014) Guidelines for the screening, care and treatment of persons with hepatitis C infection. Geneva: World Health Organization. URL: http:// apps.who.int/iris/bitstream/10665/111747/1/9789241548755_eng.pdf

39. World Health Organization (2015) Guidelines for the prevention, care and treatment of persons with chronic hepatitis B infection. Geneva: World Health Organization. URL http://apps.who.int/iris/bitstream/10665/154590/1/9789241549059_eng.pdf

Copyright: (C2017 Wang MYH. This is an open-access article distributed under the terms of the Creative Commons Attribution License, which permits unrestricted use, distribution, and reproduction in any medium, provided the original author and source are credited. 